\title{
LA TRADICIÓN IMPRESA \\ DE LOS DONAIRES DEL PARNASO (1624-1625)
}

\author{
Paolo Pintacuda \\ Università degli Studi di Pavia \\ paolo.pintacuda@unipv.it
}

$\mathrm{T}$

Todos los valientes -y no son muchos- que han venido ocupándose de los Donaires del Parnaso, primera entrega literaria de Alonso de Castillo Solórzano (quien adquiriría más fama en el campo narrativo), han tenido que enfrentarse desde el principio con una peculiaridad bibliológica que, empero, aún no ha sido enfocada y explicada de manera del todo correcta: me refiero a la circunstancia por la cual contamos con un par de documentos bibliográficos (adrede evito, de momento, el empleo del término «edición») que, a pesar de las diferencias materiales, comparten el mismo pie de imprenta: «En Madrid, por Diego Flamenco, 1624». Menos quebraderos de cabeza ocasionaría, en cambio, la segunda parte de los Donaires del Parnaso, que en la misma villa y corte, y siempre por Diego Flamenco, vio la luz al año siguiente.

Para reconstruir los avatares editoriales de la primera parte, no nos queda más remedio que volver a analizar con atención los dos impresos que transmiten la obra, empezando por su detallada descripción que, ya a partir de la portada (véanse las láminas 1a y 1b), permite reconocer considerables divergencias (los identifico con las letras que en su momento les atribuyó Jauralde Pou 1979: 753-754):

\section{$[\mathrm{A}]^{1}$}

DONAYRES / Del Parnafo. / POR DON ALONSO DE / Caftillo Solorçano, Gentilombre / del Marques del Villar. / AL EXCELENTIS ${ }^{\mathrm{MO}}$ / feñor don Antonio Sancho Dauila y Tole- / do, Marques de Velada, y de San Roman, fe / ñor de la Cafa de Villatoro y Villanueua de / Gomez, Comendador de Mançanares, por / la Orden de

1 He manejado los ejemplares R/1881 y R/1208 (falto de portada) de la Biblioteca Nacional de España, y el ejemplar R 7-9-9 de la Fundación Lázaro Galdiano de Madrid, sin haber detectado variantes de estado.

Edad de Oro, XXXVI (2017), pp. 11-28, ISSN: 0212-0429 - DOI HTTP://DX.DOI.ORG/10.15366/EDADORO2017.36.001 


\section{DONAYRES Del Parnafo.}

POR DON ALONSODE Caftillo Solorçano, Gentilombre del Marques del Villar.

\section{AL EXCELENTIS}

Mo fcñor don Antonio Sancho Dauila y Tole: do, Marques de Veladia, y de San Romala, $f_{c}$ ñor de la Cala de Villatoro, y Villanueua de Gomez, Comendador dẹ Matçanares s por la Orden de Calatraua, y Gentilom bredel Rey nueftro Señor.

\section{CONTRIVILEGIO}

En Madrid, par Diego Flamence: Año 1624:;

Lámina 1a: portada de la edición A. 


\section{DONAYRE, S DE L PAR NASO.}

por Don alonfo de Casfillo Solorçano, Gä: thombre del Margues del Villar. A| Excelentilsimo Senor Dun Antonio San. Cho Davila y Toledo, Marques cie Velada y de fan Roman, Señor de la cafa de Villa Toro y Villanuelia de Gomaz, Comendador de . Mançaozares, porla Orden de Calatrạua, y Gentslombre del Rey N.S.

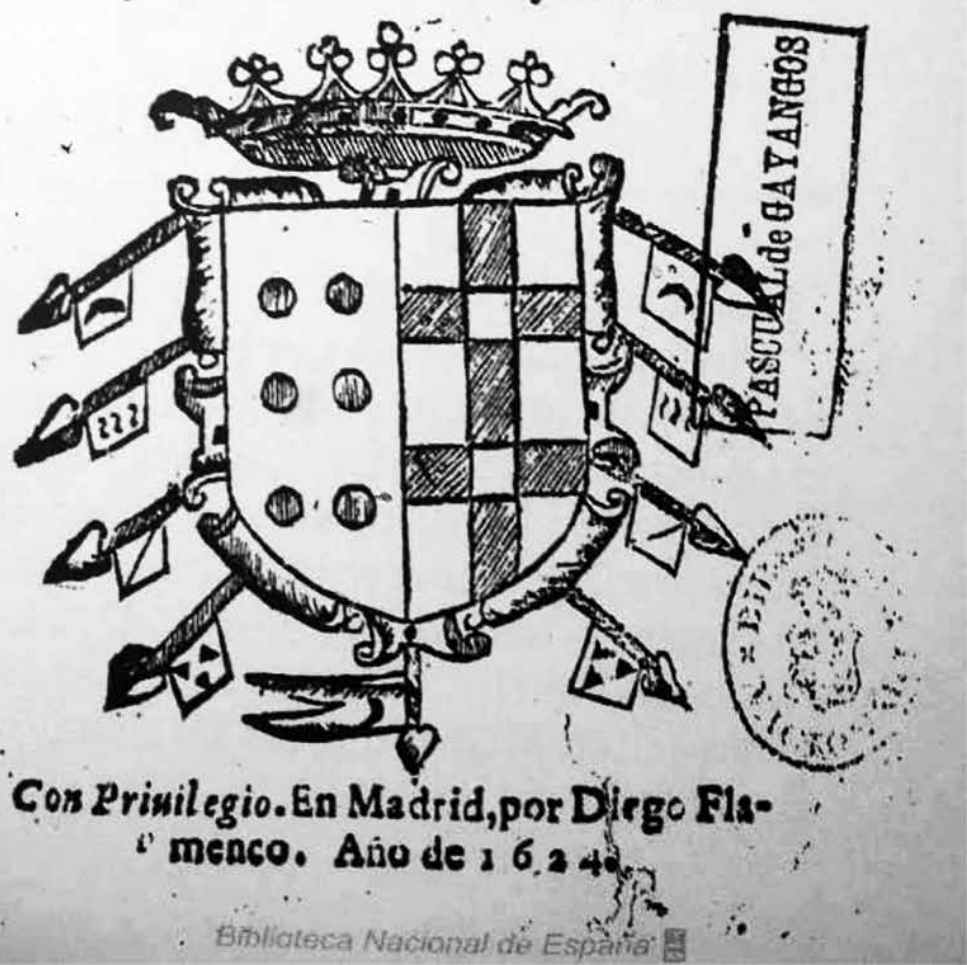

Lámina 1b: portada de la edición B. 
Calatraua, y Gentilom / bre del Rey nueftro / Señor. / [filete] / CON PRIVILEGIO. / En Madrid, por Diego Flamenco. / Año 1624.

I $^{8}, \mathrm{~A}-\mathrm{Q}^{8}$; [8], 118 [i.e. 128] ff.; en $8^{\circ}$

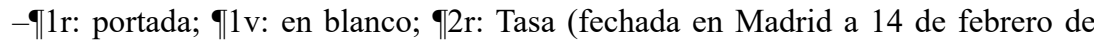
1624, por Diego González de Villarroel); $\mid 2 \mathrm{v}$ : Erratas (fechada en Madrid a 12 de febrero de 1624, por el lic. Murcia de la Llana), Suma del privilegio al autor por diez años (despachado por Diego González de Villarroel en Madrid a 5 de diciembre de 1624 [sic]); $\{3$ r: Aprobación (fechada en el Monasterio de Nuestra Señora de la Merced, a 3 de noviembre de 1623, por fr. Gabriel Téllez); $\{3 \mathrm{v}$ : Aprobación (fechada en Madrid a 10 de noviembre de 1623, por Lope de Vega Carpio); $\uparrow 4 \mathrm{r}$ : décima al autor de don Alonso Mergelina Montejo («De dos extremos hacéis»); q4v: redondillas de don Fulgencio Osorio y Pinelo («Aumentando admiraciones»); T5r: décima de don Fernando Bermúdez de Caravajal («El Fénix su pluma enriza»), décima de Sebastián Francisco de Medrano («Por tal camino guiastes»); $\lceil 5 \mathrm{v}$ : décima de don Juan Díaz de Aguilar («Llamaros por raro, solo»), décima del Maestro Juan de Villalobos («Pues el Museo te aclama»); $\uparrow 6 \mathrm{r}-\mathrm{v}$ : dedicatoria del autor a don Antonio Sancho Dávila y Toledo; $97 \mathrm{r}-\uparrow 8 \mathrm{v}$ : prólogo al lector («Cruel lector, si acaso no eres pío»); 1r-128v: texto; 128v: colofón («Con privilegio. / En Madrid, por Diego Flamenco. / Año de 1624.»).

Erratas en las signaturas: ø (en lugar de A3 y K3).

Erratas en la foliación: 16 (en lugar de ø, en f. 15v), 凤 (16), 16 (19), ø (37), 凤 (38), 87 (78), 78 (79), ø (85), 88 (en lugar de ø, en f. 87v), ø (88), 118 (128).

Elementos decorativos en los ff. $\uparrow 7 \mathrm{r}$ (friso), $\uparrow 8 \mathrm{v}$ (florón), 1r (friso), 128v (florón).

$[\mathrm{B}]^{2}$

DONAYRES / DEL PARNASO. / Por Don Alonfo de Caftillo Solorçano, Gē- / tilombre del Marques del Villar. / Al Excelentifsimo Señor Don Antonio San- / cho Dauila y Toledo, Marques de Velada y / de fan Roman, Señor de la cafa de Villa Toro / y Villanueua de Gomez, Comendador de / Mançanares, por la Orden de Calatraua, / y Gentilombre del Rey N. S. / [escudo] / Con Priuilegio. En Madrid, por Diego Fla- / menco. Año de 1624.

$\mathbf{q}^{8}, \mathrm{~A}-\mathrm{Q}^{8}, \mathrm{R}^{4}$; [8], $132 \mathrm{ff}$; en $8^{\circ}$

- $\mid 1 \mathrm{r}$ : portada; $\uparrow 1 \mathrm{v}$ : en blanco; $\mid 2 \mathrm{r}$ : Tasa (fechada en Madrid a 14 de febrero de 1624, por Diego González de Villarroel); $\mid 2 \mathrm{v}$ : Erratas (fechada en Madrid a 12 de febrero de 1624, por el lic. Murcia de la Llana), Suma del privilegio al autor por diez años (despachado por Diego González de Villarroel en Madrid a 5 de diciembre de 1624 [sic]); $\llbracket 3$ r: Aprobación (fechada en el Monasterio de Nuestra Señora de la Merced, a 3 de noviembre de 1623, por fr. Gabriel Téllez); $\{3 \mathrm{v}$ : Aprobación (fechada en Madrid a 18 de noviembre de 1623, por Lope de Vega Carpio); $\llbracket 4 \mathrm{r}$ :

He manejado los ejemplares R/13003 y R/11147 de la Biblioteca Nacional de España, sin haber detectado variantes de estado. 
décima al autor de don Alonso Mergelina Montejo («De dos extremos hacéis»); Q44v: redondillas de don Fulgencio Osorio y Pinelo («Aumentando admiraciones»); ๆ5r: décima de don Fernando Bermúdez de Caravajal («El Fénix su pluma enriza»), décima de Sebastián Francisco de Medrano («Por tal camino guiastes»); $\llbracket 5 \mathrm{v}$ : décima de don Juan Díaz de Aguilar («Llamaros por raro, solo»), décima del Maestro Juan de Villalobos («Pues el Museo te aclama»); $\mid$ 6r-v: dedicatoria del autor a don Antonio Sancho Dávila y Toledo; $\uparrow 7 \mathrm{r}-\uparrow 8 \mathrm{v}$ : prólogo al lector («Cruel lector, si acaso no eres pío»); 1r-132v: texto; 132v: colofón («CON PRIVILEGIO, / En Madrid, por Diego Flamen- / co. Año de 1624.»).

Erratas en las signaturas: ø (en lugar de C4, L4 y M4).

Erratas en la foliación: 2 (en lugar de 20), 78 (79), 85 (83).

Elemento decorativos en los ff. $\uparrow 7 \mathrm{r}$ (friso), $\uparrow 8 \mathrm{v}$ (florón), $1 \mathrm{r}$ (friso), 70r (frisos dispuestos en pie de copa), $97 \mathrm{v}$ (frisos dispuestos en pie de copa), 108v (frisos dispuestos en pie de copa).

Si Palau y Dulcet, en su inmortal Manual del librero hispanoamericano (1950: 289, n. 48384), asignaba una única entrada a los Donaires del Parnaso de 1624 -descritos según los rasgos de A-, apuntando que «De la Primera parte existe otra tirada bajo el mismo pie editorial, pero con portada distinta, y $8 \mathrm{~h} .132$ fols. (Pérez Gómez, Cieza)», en la ciclópea Bibliografía de Simón Díaz (1967: 679, n. 6765), la distinción resulta incluso más difuminada: al pie de la ficha de la obra, que se funda esta vez en B, se registran dos testimonios concretos de la Biblioteca Nacional de España, indicando sencillamente que uno de ellos presenta «muchas variantes tipográficas» (se trata de R/1208, ejemplar de A). Mucho más pormenorizado, por supuesto, es el repertorio que Franco Bacchelli reunió en el primer ensayo bibliográfico dedicado integralmente a Castillo Solórzano; tras ofrecer una descripción completa de los dos impresos, dejando constancia de los ejemplares consultados y señalando las referencias críticas, el hispanista italiano aceptaba a pies juntillas la hipótesis formulada por Palau: «Le due stampe sopra censite confermano la presenza di una doppia tiratura» (1983: 5).

Sin embargo, el trabajo que más huella parece haber dejado en los sucesivos asedios a los Donaires del Parnaso es el artículo -ya mencionado- de Pablo Jauralde (1979: 753-754), quien se limitaba a tocar el tema en el párrafo destinado a los criterios de edición de la Fábula de Polifemo - eje central de su estudio-, donde, de entrada, daba su interpretación de los impresos de 1624: «En cuanto a Donaires..., hay una doble edición -mismo año, lugar y editor- que solo se puede explicar por escasa tirada de la primera o por circunstancias extrañas»; a continuación, haciendo hincapié en las fechas de las aprobaciones que figuran en los preliminares, establecía la sucesión cronológica de las ediciones que distinguía entre sí, atribuyéndoles, como ya queda dicho, las letras A y B: «La edición con el escudo, que llamaremos 
B, [...] lleva aprobación de Lope del 18 de noviembre de 1623, en lugar de la del 10 de noviembre del mismo año que figura en la edición A». Y, finalmente, se mojaba con las diferencias textuales que existen entre las dos tiradas, afirmando que B

es la más correcta. Una ojeada rápida a las variantes confirma que la composición del libro ha sido diferente en $\mathrm{A}$ y $\mathrm{B}$, afectando también a la puntuación, mayúsculas -mucho más abundantes en B-y acentuación. Muchas variantes son por errores evidentes de A. B es más cuidadoso y también más afectado, al respetar grupos de consonantes latinas cultos, la $s$ - líquida, no admitir vacilaciones vulgares en el timbre de las vocales átonas, etc. [...] el espacio de 10 días es insuficiente para una nueva redacción de la obra; se trata, por tanto, de diferencias fortuitas en la copia sucesiva de un mismo texto.

La tesis doctoral de López Gutiérrez - primera edición moderna, tanto de la primera como de la segunda parte, de los Donaires (todavía inédita)- no aportaba nuevos elementos de reflexión acerca de la pareja de impresos de 1624: acogía (un tanto pasivamente) las observaciones de Jauralde, insistiendo en la calidad textual de la edición $\mathrm{B}$, «mucho más cuidada que la de $\mathrm{A}$, hasta tal punto que casi todas las diferencias existentes entre las dos son debidas a que se corrigen en B erratas de A» (López Gutiérrez 2003: 230).

Rafael Bonilla Cerezo, quien ha vuelto recientemente sobre la Fábula de Polifemo, confirma los deslices de la edición A, llegando a considerarla poco más que unas primeras galeradas (e invirtiendo la atribución de las letras propuesta por Jauralde, lo que podría confundir un tanto al lector):

La segunda edición de 1624, que Jauralde, López Gutiérrez y yo mismo tomamos como texto base, lleva el blasón del Marqués de Velada y tiene la misma aprobación de Lope, fechada esta vez el 18 de noviembre de 1623, sin que aparezcan ninguno de los errores $-\mathrm{y}$ desórdenes- de impresión que he reseñado. La citaré como A, distanciándome de los dos críticos, quienes por criterios cronológicos -evidentes-asignaban esta letra al «texto pirata» del 10 de noviembre. Desde un punto de vista ecdótico no puedo considerarla obra definitiva. Quizá se imprimió apresuradamente y Castillo no tuvo oportunidad de examinarla, como hubiera sido su deseo, hasta cuatro o cinco días después. De ahí que juzgue a modo de princeps (A) la que posee esa aprobación lopista del 18 de noviembre de 1623, pues la otra (B) [...] tan solo era una primera versión -es cierto, impresa- ancilar respecto de la última y definitiva. (Bonilla Cerezo 2006: 127)

Opinión bien distinta respecto a todas las que acabo de reseñar es la que exhibe el registro del catálogo informatizado de la Biblioteca Nacional de España, cuya

3 Juicios repetidos también en la cumplida información bio-bibliográfica reunida en Bonilla Cerezo 2012: 270, nota 16 . 
ficha correspondiente a A incluye la siguiente nota: «Ed. contrahecha a partir de otra con el mismo pie de imp. pero con $132 \mathrm{~h}$. y con esc. xil. en port. [es decir, a partir de B]»; sin embargo, no se aportan explicaciones ni referencias para justificarlo. Si bien no estoy tan convencido de que se pueda hablar de edición «contrahecha», en cambio comparto sin ambages la afirmación -que da la vuelta a cuanto la crítica ha venido repitiendo hasta la fecha- de que A se haya realizado a partir de B: es lo que intentaré demostrar en estas pocas páginas.

Antes que nada, quiero recalcar el hecho, ya evidenciado por Jauralde, de que nos las habemos con dos ediciones distintas, visto que todas las formas tipográficas volvieron a componerse (incluso se emplearon diversos motivos decorativos); $\mathrm{y}$, por si fuera poco, también varía el número de folios que integran el libro. Así que, aunque el número y la ordenación de los poemas no sufrieron cambios -siendo absolutamente idénticos en ambas-, el taller no trabajó mucho a plana y renglón, procedimiento que solo afecta a unos cuantos moldes.

Dicho esto, habrá que dirigir la atención a los preliminares, empezando forzosamente por la aprobación de Lope que ha constituido la única prueba aducida para determinar su sucesión cronológica (véanse las láminas 2 a y 2 b). No será ocioso observar que, salvando el asunto de las fechas - «diez de Nouiembre» (A) vs «diez y ocho de Nouiembre» (B)- y prescindiendo de la composición tipográfica y de la distribución del texto en la página, las autorizaciones del Fénix impresas en A y B se corresponden perfectamente (las tres variantes individuadas solo son pequeñas erratas de A):

Por mandado de V. Alteza he visto los Donayres del Parnaso, Autor don Alonso de Castillo Solorçano, no tienen cosa que ofenda, porque conuienen con su nombre, y son como vna muestra del viuo ingenio de su Autor, que [porque $A$ ] por estas flores, promete su dueño el fruto. Escriuiolas [Escriuolas $A$ ] en las Academias de esta Corte, donde luzieron con general [gegeral $A$ ] aplauso y aprobacion, assi de los que escriuieron en ellas como de los señores que las honran. Podra V. Alteza siendo seruido, darle la licencia que pide.

Pero tampoco estará de más recordar que la aprobación, concesión del nihil obstat por parte del censor encargado de examinar la obra, no es un trámite demasiado relevante a la hora de establecer cuándo se imprimió una edición, toda vez que representaba uno de los primeros pasos -hacia la obtención del privilegio-en el camino administrativo que llevaba a la elaboración material de un libro ${ }^{4}$.

4 Sobra recordar que la aprobación era la autorización previa necesaria para obtener la licencia de impresión, sin la cual -en un principio- no se podía empezar a componer tipográficamente las formas del libro. Una vez impresa la obra, todavía faltaba la fe de erratas, documento elaborado por el corrector oficial, tras haber averiguado la correspondencia del impreso con el original 


\section{APROBACION?}

POR mandado de V. Alteza he vilto los Donayres del Parnalo, Autor don Alonio de Caftillo Solor çano, no tienen cofa que ofenda, porque concienen con fu nombre, y fon como vna mueftra del viuo ingenio de fu Autor, porque por eftas tiores promete fu dueño el fru to. Efcrivolas en las Academias de efta Corre, dorde luzieron con gegeral aplaufo y aprouacion, afsi de los que efcrituieron en ellas, como déc los feñores que las hóran. Podriz V. Alteza, fiendo feruido, darle la licencia que pide. En Madrid, diez de Nouiembre, de 1623.

$$
\text { Iope de Vega Carpio. }
$$

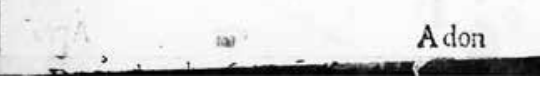

Lámina 2a: Aprobación de Lope (edición A).

\section{APROVAGION:}

POR mandadode V. Altoza he vifto los Donayres'del Parnafa, Antor don Alonfo de Caffillo Soloręano, no tienen cofa que ofenda, porque conuienen con funombre, y fon como vaa mueftra del viuo ingenio de fu Autor, que por eftas flores, promete fa dueńo el fruto. Fferi violas en las Academias defta Cortc, dóde luzieron con general aplaufo y aprobacion, afsi de los que efcriuieró en ellas como de los feíares que las honran. Podra V.Alteza fiendo fertido, darle la licencia que pide, En Madrid diez y oche de Nouiembre, de 1623 ,

\section{Lope de Vega Carpia.}

A Don

Lámina 2b: aprobación de Lope (edición B).

Téngase también en cuenta que la aprobación de Lope es el único documento legal de los Donaires del Parnaso de 1624 que presenta fechas distintas en A y B, cuando, por el contrario, el resto de disposiciones que Diego Flamenco -tal como imponía la pragmática filipina de 1558- estampó en el primer pliego de nuestras ediciones coinciden (hasta en la errata que afecta al año de concesión de la licencia):

- Aprobación eclesiástica (por fray Gabriel Téllez): 3 de noviembre de 1623.

- Suma del privilegio (por Diego González de Villarroel): 5 de diciembre de 1624 [sic].

- Erratas (por el licenciado Murcia de la Llana): 12 de febrero de 1624.

- Tasa (por Diego González de Villarroel): 14 de febrero de 1624.

Añado otra observación, de carácter general, por lo que atañe a los requisitos legales: una vez adquirida la licencia por el tiempo que el escribano de cámara determinaba en nombre del rey (en este caso fue «de diez años»), el autor, o su

autorizado; con este, finalmente, se podía solicitar la tasa, el último eslabón legal que permitía la venta de la edición. 
representante legal, no necesitaba solicitar otra para volver a imprimir la obra en la corona de Castilla dentro del plazo fijado, ni tampoco hacían falta nuevas aprobaciones. Por tanto, se antoja evidente que la autorización más tardía rubricada por Lope de ninguna manera puede relacionarse de facto con instancias relativas a una segunda edición de los Donaires. Entonces, ¿por qué razón en noviembre, apenas ocho días después de la primera aprobación, el Fénix expediría una segunda cuyo texto, para más inri, es idéntico al anterior? Y ¿cómo se explicaría su presencia en dos ediciones que llevan el mismo pie de imprenta y que, ya por sí mismas, nos plantean varios interrogantes?

Pues bien, estos misterios empiezan a despejarse cuando nos detenemos en la fe de erratas, la certificación que el revisor oficial tramitaba tras haber comprobado - a menudo de forma rápida y muy parcial, eso lo saben de sobra los que se ocupan del libro antiguo- la correspondencia entre el texto impreso y el original previamente autorizado por el Consejo: aunque normalmente (casi) nadie se toma la molestia de leérselas, averiguando de ese modo la escrupulosidad y precisión de las intervenciones censorias, a veces dicho examen puede resultar más que provechoso. En el caso de la obra de Castillo Solórzano, el licenciado Murcia de la Llana, encargado de la revisión, se conformó con señalar ocho mínimas discrepancias para luego declarar, el 12 de febrero de 1624, que «Este libro intitulado Donayres del Parnaso, con estas erratas, corresponde con su original»; se trata de las siguientes enmiendas ${ }^{5}$ :

F. 3, pág. 1, lín. 17: el, diga del.

F. 4, pág. 1, lín. 5: cruel, diga legal.

F. 5, pág. 2, lín. 20: merindable, diga merendable.

F. 39, pág. 2, lín. 3: Protocoro, diga Protocochero.

F. 97, pág. 1, lín. 10: Amnates, diga Amantes.

F. 111, pág. 1, lín. 8: ea, diga en.

F. 112, pág. 1, lín. 3: color, diga dolor.

F. 112, pág. 1, lín. 5: emplados, diga emplastros.

Sin embargo, esta misma fe de erratas se imprimió tanto en A como en B, ediciones que -según he subrayado-se realizaron volviendo a componer las formas y sin trabajar a plana y renglón; luego la exacta localización topográfica (folio y línea) de los lugares donde había que corregir el texto no puede adaptarse a una y otra. Y, en efecto, el control de los Donaires del Parnaso de 1624 permite observar que siete de las ocho referencias indicadas por Murcia de la Llana (los puntos 2-8) se corresponden únicamente con la edición B:

5 Murcia de la Llana emplea la indicación «pág. 1» para remitir al recto del folio citado, y «pág. 2» para el verso del folio. 
F. 4, pág. 1, lín. 5: en A la línea es la 4.

F. 5, pág. 2, lín. 20: en A la línea es la 17.

F. 39, pág. 2, lín. 3: en A el folio es el 38, la línea la 6.

F. 97, pág. 1, lín. 10: en A el folio es el 95, la línea la 22.

F. 111, pág. 1, lín. 8: en $A$ (f. 108r, línea 15) el texto ya es correcto.

F. 112, pág. 1, lín. 3: en A el folio es el 109, la línea la 8.

F. 112, pág. 1, lín. 5: en A el folio es el 109, la línea la 10.

Y si bien la primera, al contrario, coincide con la edición A («Fol. 3, pág. 1, lín. 17»: en B la línea es la 18), la incongruencia es mínima y podría deberse a un error involuntario del licenciado, quien se equivocó a la hora de contar las líneas de B (17 en lugar de 18); un despiste que, por mera casualidad, sí que resulta correcto en A...

De todas formas, los datos alegados parecen demostrar con cierta solidez: 1) que Murcia de la Llana cotejó el original autorizado para la imprenta con un ejemplar de la edición B;2) que esta, por consiguiente, había salido de los tórculos antes del 12 de febrero de 1624, día en el que el licenciado firmó la fe de erratas; 3 ) que solo después del 14 del mismo mes -cuando se expidió la tasa- el taller pudo imprimir el pliego de B con los preliminares (el que lleva la signatura $\uparrow$ ), necesario para poner a la venta el libro.

Pero ello implica asimismo -y no es corolario de poca monta- que las formas de A con los preliminares administrativos se compusieron posteriormente a partir de un ejemplar de B, reproduciéndolos de manera pasiva y sin preocuparse de controlar y corregir las indicaciones topográficas de las erratas (que en A no corresponden $)^{6}$. Más todavía: A copió incluso la fecha incorrecta de la Suma del privilegio (caso de haberse utilizado el documento original, no se hubiera incurrido en el mismo error $)^{7}$. Por otro lado, también introdujo unas erratas propias en todo el pliego $\llbracket$, aspecto que delata su descuido ${ }^{8}$-tal vez fruto de la prisa con que el trabajo se llevó a término- y que encaja a las mil maravillas con la escasa calidad de esta edición, ya puesta de relieve por todos los críticos:

6 De las ocho erratas indicadas por Murcia de la Llana, solo una aparece corregida en el texto de A: sin embargo, se trataría de un error tan patente de B («introduzirme / ea la Corte» en lugar de: en la Corte) que el componedor de A podría perfectamente haberlo corregido de manera autónoma.

7 Como he señalado, en el f. $\mid 2 \mathrm{v}$ la fecha de la Suma del privilegio presenta una errata manifiesta, debida a la colocación del número 4 (1624) en lugar del 3 (1623): dado que el privilegio solo pudo haberse concedido antes del control de Murcia de la Llana, el cajista evidentemente se equivocó (tal vez pensando en el año corriente).

8 Solo en dos casos enmendó un error de B: en el f. $\{2$ r, lín. 10 «Consejo» (por Censejo); y en el f. $\uparrow 7 \mathrm{v}, \mathrm{v} .14$ «segura» (por seguro). Si el primero era inmediatamente detectable, el reconocimiento del segundo resultaba favorecido por la posición en final de verso de la palabra (que debía rimar con los siguientes apresura y aventura). 
F. ๆ2r [Tasa]: lín. 16, «imprieren» (por imprimieren); lín. 20, «doy fee» (por doy esta fee).

F. \3v [Aprobación de Lope]: lín. 8, «porque» (por que); lín. 10, «Escriuolas» (por Escriuiolas); lín. 11-12, «ge-geral» (por general).

F. $\{4 \mathrm{r}$ [Décima de Alonso Mergelina Montejo]: v. 9, «doyres» (por donayres).

F. $\mid 5 \mathrm{v}$ [Décima de Juan de Villalobos]: v. 8, «aumenta» (por aumentan).

F. $\mid 7 \mathrm{r}$ [Al Lector]: v. 1, «a acaso» (por acaso).

F. ๆ8r: v. 13, «mi grata» (por a mi grata).

Con tales premisas, pues, la teoría de las dos aprobaciones de Lope viene a caerse por su propio peso, cifrándose la presencia de las dos fechas en un sencillo y muy trivial error mecánico de transmisión provocado por la inadvertida omisión en $\mathrm{A}$, durante la copia de $\mathrm{B}$, de las unidades del número (diez y ocho > diez); error que la disposición tipográfica del texto en la plana de A debió de facilitar: al contrario de B, donde «diez y ocho» figura justo al final de la línea, en A el cajista tuvo que ir aparte después de «diez»y, posiblemente, al pasar a la línea siguiente, la reprodujo tal como estaba en su modelo («de Nouiembre, de 1623»), olvidándosele componer $\left\langle\mathrm{y}\right.$ ocho» ${ }^{9}$.

En fin, a raíz de todos los argumentos alegados, y desautorizada la única prueba concreta con la que se había defendido la anterioridad de $\mathrm{A}$ respecto a $\mathrm{B}$, nos vemos en la obligación de invertir el orden temporal tradicionalmente aceptado por los críticos: respecto a las dos ediciones madrileñas de los Donaires del Parnaso fechadas en 1624, es evidente que A se realizó a partir de B (según mantiene la ficha de la Biblioteca Nacional de España).

También hay que subrayar unos datos que avalan la relación establecida, corroborándola. Antes que nada, merece la pena recordar que A (edición en octavo, igual que B) se las arregla para reducir la extensión del volumen -preocupación de carácter económico que normalmente afecta al taller que vuelve a imprimir una edición anterior-, eliminando el 'incómodo' medio pliego final de 4 folios, sin que hiciera falta quitar versos o textos del autor, ni mucho menos: se empezó a trabajar con la misma caja de 24 líneas por página de B, para luego pasar, a partir del pliego M (f. 89r y ss.), a 25 líneas; pero, sobre todo, se redujeron drásticamente los espacios en blanco entre los poemas, aprovechando también los que en B se habían dejado al final de ciertos moldes para evitar que la página terminara con el epígrafe de un poema cuyo primer verso pasaría a la siguiente (véanse, como

\footnotetext{
9 Lamentablemente, me he dado cuenta demasiado tarde -cuando ya urgía la entrega del texto- de que el expediente de aprobación de los Donaires del Parnaso de 1624 se conserva en el Archivo Histórico Nacional de Madrid (Consejo, legajo 45793): sobra decir que su consulta podría validar mi conjetura. Le debo la confirmación del dato a la amable generosidad de Fernando Bouza, quien se había referido de pasada a la existencia de este documento en Bouza 2012: 19, nota 15 .
} 
muestra, los ff. 8r, 10r, 70r, 97v, 108v). Ello llevaba consigo la forzosa renuncia a trabajar a plana y renglón, técnica cuyas ventajas por lo que toca al tiempo de composición de las formas son evidentes, y que el cajista pudo permitirse solo en unas pocas ocasiones (en la citada Fábula de Polifemo, por ejemplo).

En segundo lugar, teniendo presentes los principios de la transmisión (y, ¿por qué no?, de la crítica) textual, resulta ahora mucho más económica y convincente la explicación de los errores y descuidos de A, que, en cuanto copia hecha a la ligera, reprodujo su modelo (B) con un sinfín de erratas y malas lecturas ${ }^{10}$. A propósito de los deslices de $\mathrm{A}$, es preciso destacar un par de evidentes problemas textuales que se deben a crasos errores materiales del taller y que hasta la fecha no han sido declarados de forma conveniente.

El primero de ellos lo señalaba López Gutiérrez (2003: 229) en el estudio introductorio de su edición de los Donaires del Parnaso, observando que la edición A

tiene un error de impresión en el folio núm. 15, de tal forma que, al acabar la cara recta del mismo, se comprueba que los versos que debieran figurar en su cara vuelta se encuentran en la cara recta del folio siguiente, lo que provoca que se intercalen 24 versos del poema I, 10 entre los versos 18 y 19 del poema I, 9, con lo cual el citado I, 10 se da por concluido al final de la cara recta del folio 16, precisamente en su verso 16, pues sus 24 versos siguientes hay que leerlos en la cara vuelta del folio anterior, según he explicado arriba, mientras que los últimos versos del poema I, 9 hay que leerlos al principio de la cara recta del folio $16^{11}$.

Confieso que he salido algo mareado de los recovecos de esta descripción de dicho «error de impresión»; error que, tal vez, podría ilustrarse con más claridad prescindiendo de sus repercusiones sobre la lectura de los poemas de Castillo Solórzano.

La cuestión obedece al hecho de que el pliego B (ff. 9-16) del libro salió de los tórculos con una grave tara, al estropearse en los últimos dos folios el orden correcto de las páginas, las cuales acabaron por presentar la sucesión: 15r, [16r],

${ }_{10}$ Al revés de lo que se ha dicho hasta la fecha: las diferencias entre las dos ediciones no se deben al hecho de que B corrigió las erratas de A, sino que son el normal resultado al que lleva la copia apresurada y descuidada de un texto (que acaba corrompiendo la lección del antígrafo). Aunque se ha hablado generalmente de variantes (ni las ediciones de la Fábula de Polifemo, ni la de los Donaires del Parnaso ofrecen aparatos), la verdad es que solo se trata de errores: sin detenernos en la ortografía (mayúsculas, alternancias gráficas, etc.), un cotejo -si bien no sistemáticorevela que hay erratas casi solo en A. Sin embargo, aunque raramente, el componedor de A supo corregir errores de B: si por ejemplo echamos un vistazo a los pliegos con signatura A y B de A, comprobaremos que los gazapos no son muchos, pero tampoco escasos (18); y que solo una vez A pudo corregir la errata de su modelo. He extendido mi control a todo el texto de la Fábula de Polifemo (B, ff. 87r-97v; A, ff. 85v-96r) y la situación no varía: 11 errores introducidos por A, frente a 2 enmiendas.

11 Citaba este mismo pasaje Bonilla Cerezo 2012: 269-270, nota 17. 
[15v], 16v (razonando por formas, corresponden a las planas: B7r, B8r, B7v, B8v). La inversión de la segunda y tercera plana de la serie es evidente, porque la delatan los reclamos y los titulillos, y, sobre todo, en lo alto del verso del f. 15 se lee inequívocamente el número 16 que, en efecto, le corresponde a la plana según la paginación prevista (y, por supuesto, porque -devolviendo las páginas a su lugar ideal- los versos del poeta corren seguidos y sin tropiezos). El error, pues, no se debió al cajista - por otra parte, los dos moldes en cuestión (B7v y B8r) están bien compuestos-; ocurrió, sencillamente, que se dispusieron mal, invirtiendo su posición durante el casado (la colocación de los moldes para constituir la forma). $\mathrm{Al}$ tratarse de un volumen en octavo, el fallo se justifica sin apuros, no solo porque en este formato tanto B7v como B8r se imprimían en la misma forma, correspondiente a la cara interior del pliego ${ }^{12}$; sino porque, encima, en dicha forma las dos planas debían hallarse con la misma orientación y dispuestas una al lado de la otra, con B8r a la izquierda y B7v a su derecha. Así que el yerro de un empleado de tipografía distraído, fácil de cometer (aunque muy grave en un profesional de la imprenta), originó un pliego estragado.

Sin embargo -y se trata del otro desliz, del que solo se ha percatado Bonilla Cerezo $^{13}$-, el taller repitió el mismo despiste en el pliego L, volviendo a invertir dos moldes que ocupaban la idéntica posición de los anteriores B8r y B7v en la cara interna del pliego (L7v y L8r): el resultado, por tanto, es que por segunda vez la edición A presenta una sucesión errónea de las páginas, cuyo orden es $87 \mathrm{r}$, [88r], [87v], 88v (también aquí los reclamos y el número 88 en el verso del f. 87 son indicios definitivos).

Ahora bien, si los elementos que hemos venido acopiando insisten en probar el módico cuidado que se puso en la factura de $\mathrm{A}$-aspecto, al fin y al cabo, ya dado por asumido-, todavía se nos escapan los móviles que empujarían a reimprimir los Donaires del Parnaso con el mismo pie de imprenta. Pero antes de lanzarse al resbaladizo terreno de las hipótesis, merece la pena recordar que unas pocas semanas después de la salida de la primera edición (que, como se ha visto, pudo circular legalmente solo después del 14 de febrero de 1624), Castillo Solórzano vendía el privilegio al tipógrafo Diego Flamenco:

Sepan quantos esta carta de venta y cesión vieren como yo Don Alonso de Castillo Solorzano residente en esta villa de Madrid, digo que por quanto yo he compuesto

12 No hace falta recordar que el octavo tiene en su cara interior las planas correspondientes a las páginas 2, 3, 6, 7, 10,11, 14 y 15 del pliego (en nuestro caso, las dos afectadas fueron la $14 \mathrm{y}$ la 15). Aunque hoy disponemos de una abundante literatura crítica sobre la filología del texto impreso, le tengo especial devoción al ensayo de Garza Merino 2000, donde estas cuestiones materiales quedan magníficamente expuestas.

13 Bonilla Cerezo 2006: 126. La verdad es que tampoco aquí la exposición del error resulta fácil de seguir. 
un libro intitulado Donayres del Parnaso, y Su Magestad me hizo merced de darme licencia y privilegio para poderlo imprimir por diez años. Por tanto otorgo que vendo, cedo, renuncio e traspaso la dicha licencia y derecho que yo tengo a Diego Flamenco, impresor de libros, para que pueda usar del dicho privilegio e imprimir el dicho libro durante los dichos diez años con las mismas acciones y derechos que yo tengo que para ello le subrogo y pongo en mi asiento e lugar y es por razon de que el susodicho me ha dado e pagado ducientos reales que confieso haber recibido e pasado a mi poder... y confieso no valer mas de los dichos ducientos reales el dicho derecho que yo tengo, e si mas vale o valer puede, dello le hago gracia... En la villa de Madrid a quince dias del mes de Abril de mil seiscientos y veinte y cuatro años... Don Alonso de Castillo Solorzano. Diego Flamenco. Pasó ante mi Juan de Alayz de Pedrosa ${ }^{14}$.

El dato es de relieve porque significa que, a partir de esta fecha -repito: el 15 de abril de 1624-, el poeta perdía - cuando menos durante la década sucesivatoda forma de control sobre las futuras ediciones de los Donaires que, por tanto, saldrían únicamente al amparo de la buena voluntad del taller de Flamenco, quien posiblemente no ostentaría las mismas preocupaciones por cuidar al aspecto textual del libro que, en cambio, hubiera tenido el autor: postura que encaja muy bien con los caracteres de A. Hay más: visto que todo el volumen, incluso los documentos legales, volvió a componerse forma por forma a partir de $\mathrm{B}$-operación que requería cierto tiempo y que solo pudo empezar después del 14 de febrero (cuando se expidió la tasa, última autorización de B)-, es poco probable que la nueva edición circulara antes de la cesión del privilegio (15 de abril); y como tampoco estimo muy plausible que el privilegio se cediera durante la realización de A, no parece descabellado pensar que esa edición se preparara después del 15 de abril de 1624, o sea, cuando la licencia de imprenta ya estaba en manos de Diego Flamenco.

Con todo, quedarían por aclarar dos enigmas: qué razones concretas llevaron a la decisión de sacar una nueva edición, y cuándo salió esta de veras a la calle. Al respecto -aunque solo me atrevo a avanzar suposiciones, que necesitarían soportes documentales más firmes-, no descartaría la eventualidad de que algo tuvo que ver la preparación de la segunda parte de los Donaires del Parnaso que, publicada en 1625 siempre por Diego Flamenco, debía de estar lista ya a finales del verano de 1624, puesto que las dos aprobaciones llevan fecha del mes de septiembre (del día 23 la eclesiástica, de Sebastián Francisco de Medrano; del 25 la real, de Lope de Vega $)^{15}$. En este caso, afortunadamente, la edición no plantea controversias

14 Pérez Pastor 1907: 264-265; la ficha de los Donaires del Parnaso (n. 2148) se lee en las pp. 258-265.

15 El libro, que obtuvo el privilegio el día 1 de octubre de 1624, pudo circular después del 19 de abril de 1625 , fecha de expedición de la tasa. 
bibliográficas - por más que nos confunda la ficha de Bacchelli ${ }^{16}$, y la edición solo presenta unas variantes de estado; muy pocas, según ha revelado un control todavía incompleto:

DONAYRES / DEL PARNASO. / SEGVNDA PARTE. / A don Iuan de Zuñiga, Requesens, Cordo- / ua y Pimentel, mi señor, Marques del Vi- / llar, Comendador de Ocaña , por la / Orden de Santiago , y Gentilom- / bre de la Camara del Rey / nueftro Señor. / Por Don Alonso de Caftillo Solorçano, / Gentilombre de fu cafa. / Año [marca tipográfica con el lema «Propria / non aliena»] 1625 / CON PRIVILEGIO, / En Madrid, Por Diego Flamenco. / A cofta de Lucas Ramirez mercader de libros / Vendefe en la calle de Toledo.

$\mathbf{q}^{6}$, A-P ${ }^{8} ;$ [6], $120 \mathrm{ff}$; en $8^{\circ}$

- 1 r: portada; $\ 1 \mathrm{v}$ : en blanco; $₫ 2 \mathrm{r}$ : Tassa (fechada en Madrid a 19 de abril de 1625, por Lázaro de Ríos Angulo); $\{2 \mathrm{v}$ : Erratas (fechada en Madrid a 12 de abril de 1625 , por el lic. Murcia de la Llana), Suma del privilegio al autor por diez años (despachado por Lázaro de Ríos en Madrid a 1 de octubre de 1624); $\{3 r$ : Aprobación (fechada en Madrid, a 23 de septiembre de 1624, por Sebastián Francisco de Medrano); $\lceil 3 \mathrm{v}$ : Aprobación (fechada en Madrid a 25 de septiembre de 1624, por Lope de Vega Carpio); $\llbracket 4$ r: Declaración de las Enigmas; $\uparrow 4 \mathrm{v}$ : escudo de armas de don Juan de Zúñiga; 95 r-v: dedicatoria del autor a don Juan de Zúñiga, Requesens, Córdoba y Pimentel, Marqués del Villar, Comendador de Ocaña por la Orden de Santiago; ๆ6r-v: prólogo al lector («Culto lector, en lengua castellana»); 1r-120v: texto; 120v: colofón («Fin»).

Erratas en las signaturas: ø (en lugar de O3).

Erratas en la foliación: ø (en lugar de 16), 13 (23), 17 (24), 45 (44), 57 (53), 87 (83), 89 (85), 81 (89), 88 (100).

Grabados xilográficos (20) en los ff. 102r, 103r, 104r, 105r, 106r, 107r, 107v, 108v, $109 \mathrm{v}, 110 \mathrm{v}, 111 \mathrm{v}, 112 \mathrm{v}, 113 \mathrm{v}, 114 \mathrm{v}, 115 \mathrm{v}, 116 \mathrm{v}, 117 \mathrm{v}, 118 \mathrm{v}, 119 \mathrm{r}, 120 \mathrm{r}$.

16 Al describir los dos ejemplares de los que deja constancia, ambos custodiados por la Biblioteca Nacional de España (el uno signado como R/2814, el otro como R/13003), Bacchelli (1983: 6) anota que en el segundo «le vignette illustrative degli Enigmi sono più importanti rispetto all'esemplare precedente per cui si può desumere che anche di questa seconda parte fu fatta un'altra specie». La ambigua expresión «più importanti» (¿serían más grandes, o mejor trazadas?) se nos antoja aún más misteriosa, ya que las viñetas resultan idénticas: y, si queremos ser maniáticos, es más bien el ejemplar R/2814 el que sería preferible, sencillamente porque las xilografías han salido mejor impresas, por razones de entintado (o de mejor conservación del ejemplar) y, sobre todo, porque el papel es de calidad superior (un poco más grueso). Si más abajo Bacchelli insiste, manteniendo que «anche questa, come l'edizione del 1624, deve aver avuto una seconda tiratura date le differenze grafiche riscontrate negli esemplari descritti» - no queda muy claro a qué diferencias gráficas se refiere...-, es posible que solo se trate de un problema terminológico, y que él quisiera aludir a las variantes de estado; que sí, las hay, pero que no presuponen en absoluto la realización (como en el caso de los Donaires de 1624) de dos ediciones distintas. También en su descripción de la edición incurrió en algunos despistes. He manejado los mismos ejemplares. 
Como esta nueva entrega poética no la costeó el autor, sino el librero Lucas Ramírez, es posible que este -con vistas a su inminente publicación- hubiera considerado provechoso (desde una perspectiva meramente comercial) disponer de un cierto número de ejemplares de la primera parte, para poderla ofrecer y vender junto con la segunda: por ello, o porque la edición $B$ ya estaba agotada, $o$ tal vez porque las existencias de la tirada habían quedado en manos de Castillo, o bien por razones que se nos escapan, Ramírez y Delgado (quien ahora poseía el privilegio) decidieron reimprimir el libro, igual de aprisa y corriendo, dando así forma a la edición A; y posiblemente se le ocurrió hacerlo durante el último tercio de 1624, es decir, cuando, adquirida la licencia por el autor, iba concretándose la realización de la segunda parte.

De todas formas, es cierto que la segunda parte se afrontó con cierta calma: entre la fecha de concesión del privilegio (1 de octubre de 1624) y la de la tasa (19 de abril de 1625) median más de seis meses, cuando solo habían pasado dos en el caso de los Donaires del '24 (y se trata de volúmenes en esencia de la misma extensión). Esta breve dilación no resulta en modo alguno sorprendente, ya que era común la impresión de libros incluso varios años después de que hubiesen conseguido el privilegio ${ }^{17}$; en nuestro caso, tal vez sea posible vislumbrar una explicación concreta si tomamos en consideración los intereses -¿más candentes?- de Castillo Solórzano, quien por aquellos días andaba engolfado con otra imprenta (la de la viuda de Alonso Martín) y con otro librero (Alonso Pérez) en la edición de sus Tardes entretenidas, colección con la que estrenaría su feliz carrera como autor de novelas $\operatorname{cortas}^{18}$. Y también si le echamos un vistazo a la actividad de Diego Flamenco en dicho periodo: tras la composición e impresión del poema $E l$ Bernardo de Bernardo de Balbuena, volumen en cuarto de 280 folios cuya fe de erratas lleva fecha del 18 de septiembre ${ }^{19}$, que debió de ocupar al taller gran parte del verano de 1624, el siguiente libro importante salido de sus prensas (168 folios, en octavo) fueron las Divinas y humanas flores de Manuel de Faria e Sousa, que pudieron contar con la fe de erratas el 25 de noviembre y con la tasa solo un día después $^{20}$. Posteriormente, el compromiso más acucioso de la tipografía parece

17 Buena muestra de ello es La casa de la razón y el desengaño de Alonso Remón, que el mismo Flamenco imprimió (a costa de Juan Casar) en 1625: si la fe de erratas lleva la fecha del 27 de septiembre de 1625 y la tasa la del 2 de octubre, el libro había obtenido el privilegio el 7 de noviembre de 1620 .

18 A raíz de las aprobaciones del 18 y el 23 de septiembre de 1624, el privilegio fue otorgado el 24 del mismo mes; el libro pudo circular en la primavera siguiente, visto que la fe de erratas se firmó el 15 de marzo de 1625 y la tasa el 21.

19 El privilegio se había concedido el 9 de julio de 1624, mientras que la tasa se expediría el 28 de septiembre.

20 Otro caso de realización 'tardía' respecto al privilegio, que se había otorgado el 27 de julio de 1623. 
haber sido la realización de dos obras de Pierre Matthieu traducidas por Juan Pedro Mártir Rizo: en primer lugar, la Historia de la prosperidad infeliz de Felipa de Catanea (60 folios en octavo), que se acometió entre el 9 y el 24 de enero de $1625^{21}$; y, de seguido, la Historia de la muerte de Enrico el grande, cuarto rey de Francia deste nombre (104 folios en octavo), ya en la segunda década de febrero del mismo año ${ }^{22}$. Junto a estas obras mayores, del taller de Flamenco también se difundieron durante este bienio productos de menor envergadura, sobre todo diferentes Avisos y Relaciones formados por un pliego, o poco más, que constituían una fuente de ingresos regular y que, por su valor noticioso, había que imprimir sin demora.

Admito que todo este acopio de nombres, títulos y fechas, que ni siquiera puede considerarse completo (es posible que entre 1624 y la primavera de 1625 salieran de las prensas de Flamenco más libros), no demuestra nada; sin embargo, eso sí, permite observar que -insisto: por lo que nos consta- hubo unos meses (finales de noviembre y diciembre del '24; finales de febrero y marzo del '25) en los que el taller estuvo relativamente libre de las ocupaciones conexas con las obras arriba citadas. Y quién sabe si justo en tales intervalos habría que colocar la composición de la edición A de los Donaires del Parnaso y de su segunda parte...

En fin, si no he podido arrojar mucha luz sobre estos últimos aspectos de la tradición impresa de la poesía de Castillo Solórzano, sí creo haber despejado definitivamente las incertidumbres acerca de las dos ediciones de la primera parte de 1624: por tanto, para dejar sentado el nuevo orden cronológico, propondría -evitando la inversión de las siglas A y B ya avanzada por Bonilla Cerezo (2006: 127), que podría dar pie a confusiones, y a costa de manifestar mi escasa originalidadel uso de las letras griegas $\alpha$ (en lugar de B) y $\beta$ (en lugar de A).

\section{BIBLIOGRAFÍA}

BaCchelli, Franco (1983). Per una bibliografia di Castillo Solórzano. Verona: s. n.

Bonilla CEREzo, Rafael (2006). Lacayo de risa ajena. El Gongorismo en la «Fábula de Polifemo» de Alonso de Castillo Solórzano. Córdoba: Diputación de Córdoba.

- (2012). «Alonso de Castillo Solórzano: bio-bibliografía completa». Tintas. Quaderni di letterature iberiche e iberoamericane, 2, pp. 243-282.

BouzA, Fernando (2012). «Dásele licencia y privilegio». Don Quijote y la aprobación de libros en el Siglo de Oro. Madrid: Akal.

Garza Merino, Sonia (2000). «La cuenta del original». En Imprenta y crítica textual en el Siglo de Oro. Valladolid: Centro para la Edición de los Clásicos Españoles, pp. 65-95.

\footnotetext{
21 Según consta por las fechas del privilegio y de la fe de erratas, la tasa se expidió el 28 de enero.

22 Adquirido el privilegio el 8 de febrero, ya podía disponer de la fe de erratas el 18 (y el 22 de la tasa).
} 
Jauralde Pou, Pablo (1979). «Alonso de Castillo Solórzano, Donaires del Parnaso y la Fábula de Polifemo». Revista de Archivos, Bibliotecas y Museos, LXXXII, pp. 727-766.

LÓPEZ GutiÉRREZ, Luciano (2003). «Donaires del Parnaso» de Alonso de Castillo Solórzano: edición, estudio y notas [tesis doctoral]. Madrid: Universidad Complutense.

Palau y Dulcet, Antonio (1950²). Manual del librero hispanoamericano, III. Barcelona-Madrid: Antonio Palau.

PÉrez Pastor, Cristóbal (1907). Bibliografía madrileña. Parte tercera (1621 al 1625). Madrid: Tipografía de la Revista de Archivos, Bibliotecas y Museos.

Simón Díaz, José (1967). Bibliografía de la literatura hispánica, VII. Madrid: CSIC.

Recibido: $15 / 09 / 2017$

Aceptado: 13/11/2017

\section{LA TRADICIÓN IMPRESA DE LOS DONAIRES DEL PARNASO (1624-1625)}

RESUMEN: El artículo aclara las relaciones textuales entre las dos ediciones de Donaires del Parnaso, salidas con el mismo pie de imprenta (Madrid, Diego Flamenco, 1624), y da la vuelta a la sucesión cronológica tradicionalmente admitida por la crítica, demostrando que la llamada "edición A" es en cambio una edición hecha, con escaso cuidado, a partir de un ejemplar de la "edición B". Al mismo tiempo, se detectan y declaran de forma conveniente una serie de errores materiales durante la preparación de la "edición A".

Palabras Clave: Donaires del Parnaso, Castillo Solórzano, Lope de Vega, Murcia de la Llana, Filología del texto impreso.

\section{The Printed Tradition of Donaires del Parnaso (1624-1625)}

ABSTRACT: The article clarifies the textual relations between the two editions of Donaires del Parnaso, published with the same imprint (Madrid, Diego Flamenco, 1624), and turns the chronological sequence traditionally admitted by critics, proving that the call "Edition $A$ " is instead an edition made, with little care, from a copy of the "edition B". At the same time, material errors produced during the preparation of the "edition $A$ " are conveniently detected and declared.

Keywords: Donaires del Parnaso, Castillo Solórzano, Lope de Vega, Murcia de la Llana, Textual bibliography. 


\section{EDAD DE ORO}

Revista de Filología Hispánica XXXVI






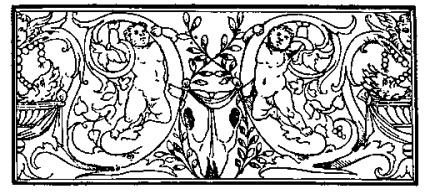

\section{Edad de Oro. Revista de Filología Hispánica}

ISSN: 0212-0429

Dirección:

Teodosio Fernández

Secretaría y edición:

José Ramón Trujillo

Consejo de redacción:

Manuel Piqueras

Blanca Santos

Admisión de originales:

María Jesús Zamora

Edad de Oro

Departamento de Filología Española

Universidad Autónoma de Madrid

28049 Madrid (España)

Tfno.: +0034914974090

correo: mariajesus.zamora@uam.es

Distribución, suscripción y venta:

Servicio de Publicaciones de la UAM

Universidad Autónoma de Madrid

28049 Madrid (España)

Intercambio de publicaciones:

Biblioteca de la Facultad de Filosofía y

Letras (UAM)

Universidad Autónoma de Madrid

28049 Madrid (España)
Comité científico internacional:

Carlos Alvar (Univ. de Ginebra)

Ignacio Arellano (Univ. de Navarra)

Javier Blasco (Univ. de Valladolid)

Alberto Blecua (UAB)

Jean Canavaggio (Univ. de París X)

Laura Dolfi (Univ. de Turín)

Aurora Egido (Univ. de Zaragoza)

Víctor García de la Concha (RAE)

Luciano García Lorenzo (CSIC)

Joaquín González Cuenca (Univ. de

Castilla-La Mancha)

Agustín de La Granja (Univ. de Granada)

Begoña López Bueno (Univ. de Sevilla)

Michel Moner (Univ. de Toulouse III)

Joan Oleza (Univ. de Valencia)

Alfonso Rey (Univ. de Santiago)

Lina Rodríguez Cacho (Univ. de Salamanca)

Leonardo Romero Tobar (Univ. de Zaragoza)

Aldo Ruffinatto (Univ. de Turín)

Lía Schwartz (City University of New York)

Han colaborado en este volumen:

Departamento de Filología Española (UAM)

Facultad de Filosofía y Letras (UAM)

Edad de Oro se recoge, entre otras, en las siguientes bases de datos: SCOPUS, MLA Database, HLAS, Latindex, PIO-Periodical Content Index, ISOC, Dialnet, MIAR, ERIH Plus, DICE, Sumaris CBUC, Ulrich's. Se encuentra evaluada en CIRC: A; MIAR difusión ICDS live 2016: 10.0; INRECH; SCImago Journal \& Country Rank: H Index 3, SJR SCImago Journal \& Country Rank 0,1, Q4; RESH índice de impacto: 0.041; ERIH: A INT1; Carhus Plus+2014: C. 